\title{
Effective Antimicrobial Coatings Containing Silver-Based Nanoclays and Zinc Pyrithione
}

\author{
Mercedes Monte-Serrano1, Patricia Fernandez-Saiz¹, Rafael M Ortí-Lucas ${ }^{2,3}$ and Barbara Hernando ${ }^{4 *}$ \\ ${ }^{1}$ Nanobiomatters Research and Development SL, Paterna, Valencia, Spain \\ ${ }^{2}$ Preventive Medicine Department, Hospital Clinico Univesitario, Valencia, Spain \\ ${ }^{3}$ Social Medicine and Public Health Department, Universidad Católica 'San Vicente Mártir', Valencia, Spain \\ ${ }^{4}$ Nanobiomatters BactiBlock SL, Paterna, Valencia, Spain
}

\begin{abstract}
Increased antibiotic resistance in human pathogens leads to the development of new preventive measures. The introduction of antimicrobial materials and surfaces provides an alternative tool for controlling harmful microorganisms This article is focused on a study regarding the potential role of two new antimicrobial surface coatings in the control of infection spread. The method applied was to compare the antimicrobial activity of BactiBlock ${ }^{\circledR}$-treated coatings respect to untreated coatings, which were used as control, following international standards. The antibacterial activity of two antimicrobial polymer-based coatings containing silver-based antimicrobial layered silicate additive (BactiBlock ${ }^{\circledR} 635$ A1 and BactiBlock ${ }^{\circledR} 655$ A0) was tested according to JIS Z 2801 against S. aureus, MRSA, VRE, K. pneumoniae, P. aeruginosa, A. baumannii and E. coli. BactiBlock ${ }^{\circledR} 635 \mathrm{~A} 1$ also contains $0.25 \%$ of zinc pyrithione $(\mathrm{ZnP})$. The antifungal activity was tested according to ISO 846 against $A$. niger. The two coatings presented a strong antibacterial broad-spectrum activity $(R \geq 2, p<0.01)$. The coating with $\mathrm{ZnP}$ also showed a strong antifungal activity, since no fungi growth was detected on the treated surface after 4 weeks. Nevertheless, these findings support the potential of these polymer-based coatings as a tool that would help to prevent the colonization of inert surfaces by harmful microorganisms and protect patients and consumers who are exposed daily.
\end{abstract}

Keywords: Silver; Zinc pyrithione; Antimicrobial coatings; Surface protection; Infection control

\section{Introduction}

Antimicrobial materials and surfaces are being increasingly important to control pathogenic microorganisms. There are a wide variety of antimicrobial technologies which are being investigated and developed to protect surfaces [1].

A most prominent technology is the incorporation of inorganic antimicrobials - most commonly the silver ion, $\mathrm{Ag}^{+}[2]$. Silver is a naturally occurring element with great effectiveness at low concentrations and a well-known antimicrobial broad-spectrum, as well as being widely recognized as safe for human contact [3]. The mechanism of action of the ionic silver is related to their interaction with sulfhydryl (thiol) groups. Thus, ionic silver interacts with thiol groups in enzymes and not only disrupts folic acid synthesis, but it also disrupts protein synthesis, inhibits DNA synthesis, disrupts electron transport and interferes with cell wall synthesis [4]. To date, there has been no evidence regarding a hypothetical microbial resistance to silver due to its multi-target antimicrobial action makes it almost impossible for the bacteria to mutate in a way that would lead to resistance [5].

Recent technological innovations are focused on the incorporation of silver on inorganic vehicles such as laminar clays, zeolites or soluble phosphate glasses in order to protect silver from oxidationreduction reactions and to control silver release from the surface to the environment. Surface modification of clays allows the creation of new materials and new applications [6]. This process acts as a previous step before the incorporation of silver into polymeric matrixes in order to produce active materials [7].

Another well-known biocide agent is Zinc pyrithione $(\mathrm{ZnP})$. Its development in the 1950s was based on the development of aspergillic acid, the natural antibiotic from Aspergillus niger [8]. $\mathrm{ZnP}$ inhibits fungal growth through copper import and damage to iron-sulphur proteins and also depolarizes membrane electropotential in fungi [9]. $\mathrm{ZnP}$ is the most common material used for dandruff treatment globally, and recently it is being used as active compound in other antibacterial approaches [10,11].

One of the most important potential uses for antimicrobial materials is in surface coatings [12]. Biofilm formation on material surfaces represents a serious problem in society from both an economical and health perspective [13]. For some time, scientists and healthcare professionals have considered in the importance of surfaces as reservoirs of microbes $[1,14,15]$. In this context, the incorporation of active ingredients (such as nanoparticles of silver and $\mathrm{ZnP}$ ) in coatings has shown promising results in surface protection from biofilm formation, preventing the spread of infection for transmission to food and humans by contact [16]. Other advantages in economic and environmental aspects are less frequency of repainting, labor and chemical cost reductions.

BactiBlock $^{\circledast}$ is a novel antimicrobial silver-based organomodified layered silicate additive. These silver-based nanoclays have the ability

*Corresponding authors: Barbara Hernando, Nanobiomatters BactiBlock SL, Paterna, Valencia, Spain, Tel: +34 963116 857; E-mail: bhernando@bactiblock.com

Received October 25, 2015; Accepted October 30, 2015; Published November 06, 2015

Citation: Monte-Serrano M, Fernandez-Saiz P, Ortí-Lucas RM, Hernando B (2015) Effective Antimicrobial Coatings Containing Silver-Based Nanoclays and Zinc Pyrithione. J Microb Biochem Technol 7: 398-403. doi:10.4172/1948-5948.1000245

Copyright: ㄷ 2015 Monte-Serrano M, et al. This is an open-access article distributed under the terms of the Creative Commons Attribution License, which permits unrestricted use, distribution, and reproduction in any medium, provided the original author and source are credited. 
to evenly distribute silver across the matrixes, and thus provide them a uniform antimicrobial activity [17]. The present study was conducted to determine the in vitro antimicrobial capacity of two BactiBlock ${ }^{\otimes}$ treated polymer-based surface coatings, one also functionalized with $\mathrm{ZnP}$. Besides, the minimal inhibitory concentration of BactiBlock ${ }^{\oplus}$ and antifungal effectiveness of $\mathrm{ZnP}$ were evaluated.

\section{Materials and Method}

\section{Materials}

BactiBlock $^{\otimes}$ is the trade-marked name for the antimicrobial silver-based organomodified layered silicate additives developed by Nanobiomatters BactiBlock S.L. (Paterna, Spain). BactiBlock ${ }^{\circledR} 101$ R4.47 (below referred to as R4.47) is a silver-based additive which uses an organomodified phyllosilicate as carrier. It is a highly efficient antimicrobial additive because of its high specific surface area (D50 $=2.5$ $\mu \mathrm{m})$. The organomodified nanoclay allows silver dispersion and distribution into the coating and all over the surface when it is applied. Unmodified clay (natural phyllosilicate) was used for comparative purposes.

BactiBlock $^{\oplus} 655$ A0 Antimicrobial Flooring Protection (BB655A0) is a polyurethane monolayer coating designed to protect all kind of floors against microorganisms. BactiBlock ${ }^{\circledR} 635$ A1 Antimicrobial Coating FG (BB635A1) is an antimicrobial acrylic coating designed to inhibit the growth of both bacteria and fungi, thanks to the addition

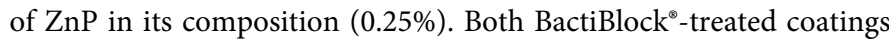
contain $0.3 \%$ R 4.47 . Untreated polyurethane and acrylic coatings were used as control to compare antimicrobial test results. No additional information regarding the additive and coatings components is shown for confidentiality terms.

\section{Silver content in $\mathbf{R} 4.47$}

Energy dispersive X-ray fluorescence (EDXRF Bruker Tiger S8) was used to determine silver content in R4.47. Pressed clay powder pellets were prepared using boric acid as a support. Each sample was vacuum dried for $2 \mathrm{~h}$ at $105^{\circ} \mathrm{C}$, weighed together with the support and ground in planetary mill at $700 \mathrm{r} / \mathrm{min}$ for $20 \mathrm{~s}$. Then the samples were pressed with 80 ton pressure for $20 \mathrm{~s}$.

\section{Bacterial strain and growth conditions}

Staphylococcus aureus (CECT 240, ATCC 6538P), Escherichia coli (CECT 516, ATCC 8739), methicillin-resistant Staphylococcus aureus (MRSA) (CECT 5190, ATCC 43300), vancomycin-resistant Enterococcus faecium (VRE) (CECT 5253), Pseudomonas aeruginosa (CECT 110, ATCC 10145), Acinetobacter baumannii (CECT 452, ATCC 15308) and Klebsiella pneumoniae (CECT 8453, ATCC 4352) obtained from the Spanish Type Culture Collection (Valencia, Spain). The strains were stored in Tryptone Soy Broth (TSB) with $20 \%$ glycerol at $-80^{\circ} \mathrm{C}$ until needed. For experimental use, the stock culture from each microorganism was maintained by regular subculture on Tryptone Soy Agar (TSA) slants at $4^{\circ} \mathrm{C}$ and transferred monthly. Using the inoculation loop, bacteria was removed to $10 \mathrm{ml}$ of TSB and was incubated at $37^{\circ} \mathrm{C}$ overnight. A $100 \mu \mathrm{l}$ aliquot from the overnight culture was again transferred to TSB and grown at $37^{\circ} \mathrm{C}$ to the midexponential phase of growth. The mid-exponential phase culture was served as the inoculum in the susceptibility tests. The cell density was determined by optical density at $600 \mathrm{~nm}$, adjusting to $10^{8} \mathrm{CFU} / \mathrm{ml}$ (CFU for colony forming units).

\section{Fungal strains and growth conditions}

Aspergillus niger (CECT 2807, ATCC 6275) obtained from the Spanish Type Culture Collection (Valencia, Spain). The fungus was grown on complete agar medium (CM; described in ISO 846:1997) [18] and was harvested from isolates after incubation at $28^{\circ} \mathrm{C}$ for 6 days. Then, it was suspended in distilled water. The suspension was then filtered through sterile gauze to remove mycelium and adjusted to $10^{7}$ spores $/ \mathrm{ml}$.

\section{Minimal inhibitory concentrations of R4.47}

To evaluate the effectiveness of R4.47, microbial growth was evaluated according to the macro-dilution method described by the Clinical and Laboratory Standards Institute [19]. For this method, different concentrations of the powder additive were introduced in sterile bottles containing TSB. For each bacterium, were tested: 0 , $3,15,30,50,100,200,300,400$ and $500 \mu \mathrm{g} / \mathrm{ml}$. After $15 \mathrm{~min}$, tubes were inoculated with each microorganism in mid-exponential phase obtaining approximately a final concentration of $10^{5} \mathrm{CFU} / \mathrm{ml}$, and incubated at $37^{\circ} \mathrm{C}$ for $24 \mathrm{~h}$. Then, serial decimal dilutions were made and $1 \mathrm{ml}$ from each dilution was sub-cultivated on TSA plates. Finally, plates were read after overnight incubation at $37^{\circ} \mathrm{C}$. These results were expressed as $\mathrm{CFU} / \mathrm{ml}$ and compared with a control sample without additive. Three different batches of R4.47 in duplicate were used.

\section{Antifungal effectiveness of $\mathrm{ZnP}$}

To evaluate the effectiveness of $\mathrm{ZnP}$, Aspergillus niger growth was evaluated by disk diffusion (Kirby-Bauer) susceptibility test according to standards of the National Committee for Clinical Laboratory (NCCLS) [20]. $150 \mathrm{~mm}$ diameter CM plates were seeded with $0.2 \mathrm{ml}$ of the spore suspension. Then, $6 \mathrm{~mm}$ diameter sterile disks of absorbent paper were placed on plates and $0.02 \mathrm{ml}$ of $\mathrm{ZnP}$ solutions $(0.0 \%, 0.3 \%$, $0.5 \%, 1.0 \%$ and $1.5 \%$ ) were loaded on the paper disks. Finally, plates were incubated at $28^{\circ} \mathrm{C}$ for 7 days. Each sample was tested in triplicate.

\section{Antibacterial effectiveness of BactiBlock ${ }^{\circledR}$-treated products}

To evaluate the effectiveness of the R4.47 when incorporated in polymeric-based coatings (BB655A0 and BB635A1), bacterial growth was evaluated according to standard protocol for antimicrobial surfaces JIS Z 2801:2012 (JIS stands for Japanese Industrial Standard), which is equivalent to International method ISO 22196:2011 [21]. For this method, each sample $(5 \times 5 \mathrm{~cm})$ was inoculated with $6.25^{\star} 10^{5}$ $\mathrm{CFU}$ and incubated at $37^{\circ} \mathrm{C}, 100 \% \mathrm{RH}$ for 24 hours. Then, $0.1 \mathrm{ml}$ from each tube was sub-cultivated on TSA plates. Finally, plates were read after overnight incubation at $37^{\circ} \mathrm{C}$. Three samples were tested in triplicate. The results were expressed as final CFU/ml and compared with a control sample, corresponding to the same product but without additive in its composition. The value of antimicrobial activity of the samples tested by the Standard JIS Z 2801 was determined through the following formula: $\mathrm{R}=\log (\mathrm{B} / \mathrm{C})$, where $\mathrm{B}$ is the average of the number of viable cells of bacteria on the untreated test piece after $24 \mathrm{~h}$, and $\mathrm{C}$ is the average of the number of viable cells of bacteria on the antimicrobial test piece after $24 \mathrm{~h}$. When $\mathrm{R} \geq 2.0$, the sample is considered to present biocidal properties.

\section{Antifungal effectiveness of BB635A1}

The antifungal effectiveness of BB635A1 was analyzed by visual examination following the International Standard ISO 846:1997 [18], which describes the standard test method developed to determine and 
evaluate the effect of fungi on polymeric materials. Samples were placed on CM plates. Then, the surface was inoculated with $0.1 \mathrm{ml}$ of the spore suspension and incubated at $25^{\circ} \mathrm{C}, 100 \%$ HR for 28 days. After each week, pictures about fungi growth in each sample were done. A control sample corresponding to equivalent BB635A1 product but without additive in its composition was used to compare visual examination. Three samples were evaluated in triplicate.

\section{Statistical analysis}

The data is presented as the mean \pm standard error of the mean. An ANOVA analysis was performed using the IBM SPSS Software v.22 to compare the bacterial counts between the BactiBlock ${ }^{\circledR}$-treated coatings and the non-treatment samples. The level of significance was set at a p-value $<0.01$.

The antifungal activity of BB635A1 was determined by visual comparison with control samples for different periods of time (1, 2, 3 and 4 weeks), according to ISO 846 .

\section{Results}

Two BactiBlock ${ }^{\circledast}$ surface coatings were tested to determine their antimicrobial capacity according to international standards assays. BactiBlock $^{\diamond}$ coatings are functionalized with a novel antimicrobial silver-based organomodified layered silicate additive (R4.47), which have the ability to evenly distribute silver across the matrixes, and thus provide them a uniform antimicrobial activity. Firstly, a chemical and microbiological characterization of R4.47 was done. Semi-quantitative cheminal analysis of R4.47 reported silver contents of $1.91 \pm 0.03 \%$ in the composition. No silver was detected in unmodified nanoclays. The antimicrobial evaluation tests of R4.47 were performed to detect its minimum inhibitory concentration (MIC) for each microorganisms included in the study. As R4.47 silver nanoclay is not soluble in water, the antibacterial activity was evaluated preparing suspensions at different concentrations. Table 1 shows the bacterial counts of the previous suspension to the first one that presented turbidity due to bacterial growth, which was considered as the MIC value. Results report that R4.47 has strong effectiveness against both bacteria and fungi. Results values obtained ranging from 3 to $300 \mu \mathrm{g} / \mathrm{ml}$ as maximum corresponding to 0.057 to $5.7 \mu \mathrm{g} / \mathrm{ml}$ of pure Ag (Table 1).

Antifungal effectiveness of $\mathrm{ZnP}$ was also performed to determine the optimal concentration to include in the formulation of active coatings. The growth inhibition of $A$. niger is noted from solutions with $0.3 \% \mathrm{ZnP}$. A delay of sporulation is also observed at this concentration. The zone of inhibition and delay were $16.00 \pm 0.58 \mathrm{~mm}$ and $51.67 \pm$ $1.20 \mathrm{~mm}$, respectively. Furthermore, higher $\mathrm{ZnP}$ concentrations do not significantly improve outcomes.

After confirming antimicrobial activity of active agents, coatings were tested for all the microorganisms. Table 2 and Table 3 collect the results of antibacterial tests carried out with BB655A0 and BB635A1 respectively. Results show bactericide activity against all the bacteria tested according to the JIS Z 2801, where the log reduction (R) obtained are between 2.21 and 5.99, being these values higher than 2 which is the threshold value for bactericide activity. All of the bacterial concentrations in testing samples are significantly lower than control samples ( $\mathrm{p}$-value $<0.01)$. When comparing the results between the two products, the addition of $\mathrm{ZnP}$ to BB635A1 is associated with increased antibacterial activity, since its $R$ values were higher than $R$ values obtained of BB655A0 (compare results presented in Table 2 and 3).

Finally, BB635A1 also was tested according to ISO 846:1997 for analyzing antifungal activity of the coating, thanks to the addition of $\mathrm{ZnP}$ in its formulation. Figure 1 shows the $A$. niger growth after 4 weeks of incubation, reporting a total colonization of the fungi in the control sample surface but not in the BB635A1-coated sample surface.

\section{Discussion}

After analysis of antimicrobial activity of the two provided coatings, results show a very high log reduction (R) values for all the bacteria tested exceeding the values required by the international standard (JIS Z 2801). Both BB635A1 and BB655A0 obtained a significant reduction for all the pathogens tested compared to control samples ( $\mathrm{p}$-values $<0.01$ ), confirming the effective antibacterial activity of the BactiBlock ${ }^{\circledR}$-treated coatings. These results were expected by us since the two coatings tested (BB655A0 and BB635A1) contain 0.3\% R4.47 corresponding to $60 \mu \mathrm{g} / \mathrm{ml}$ of pure silver, which is a concentration much higher than the MIC value of R4.47 for all the microbes. These MIC values obtained are less than the amount of active agent needed in comparation with other additives tested in previous studies [22].

Based on our results, we can confirm silver has strong antimicrobial activity against Gram-positive and Gram-negative, including drug-

\begin{tabular}{|c|c|c|c|}
\hline \multicolumn{2}{|r|}{ Microorganism } & $\log _{10} \mathrm{CFU} / \mathrm{ml} \pm \mathrm{SE}$ & MIC of BactiBlock@ $101 \mathrm{R} 4.47(\mu \mathrm{g} / \mathrm{ml})$ \\
\hline \multirow{3}{*}{ 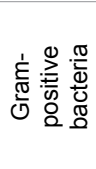 } & $\begin{array}{l}\text { Staphylococcus aureus } \\
\text { (CECT 240, ATCC 6538P) }\end{array}$ & $5.68 \pm 0.26$ & 3 \\
\hline & $\begin{array}{l}\text { Methicillin-resistant Staphylococcus aureus } \\
\text { (CECT 5190, ATCC 43300) }\end{array}$ & $0.00 \pm 0.00$ & 100 \\
\hline & Vancomycin-resistant Enterococcus faecium (VRE) (CECT 5253) & $5.50 \pm 0.17$ & 100 \\
\hline \multirow{4}{*}{ 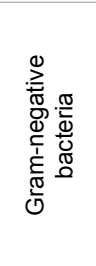 } & $\begin{array}{l}\text { Klebsiella pneumoniae } \\
\text { (CECT 8453, ATCC 4352) }\end{array}$ & $0.00 \pm 0.00$ & 15 \\
\hline & $\begin{array}{l}\text { Acinetobacter baumannii } \\
\text { (CECT 452, ATCC 15308) }\end{array}$ & $5.38 \pm 0.15$ & 30 \\
\hline & $\begin{array}{c}\text { Escherichia coli } \\
\text { (CECT 516, ATCC 8739) }\end{array}$ & $0.00 \pm 0.00$ & 100 \\
\hline & $\begin{array}{l}\text { Pseudomonas aeruginosa } \\
\text { (CECT 110, ATCC 10145) }\end{array}$ & $1.41 \pm 0.40$ & 300 \\
\hline$\frac{0}{2}$ & $\begin{array}{c}\text { Aspergillus niger } \\
\text { (CECT 2807, ATCC 6275) }\end{array}$ & $1.88 \pm 0.14$ & 3 \\
\hline
\end{tabular}

The minimum inhibitory concentration was considered the lowest concentration suspension of R4.47 that presented no visible growth of a microorganism after overnight incubation. CECT, Spanish type culture collection; ATCC, American type culture collection. CFU, colony-forming unit. SE, standard error

Table 1: Minimal inhibitory concentrations (MIC) of BactiBlock ${ }^{\circledR} 101$ R4.47. 
Citation: Monte-Serrano M, Fernandez-Saiz P, Ortí-Lucas RM, Hernando B (2015) Effective Antimicrobial Coatings Containing Silver-Based Nanoclays and Zinc Pyrithione. J Microb Biochem Technol 7: 398-403. doi:10.4172/1948-5948.1000245

\begin{tabular}{|c|c|c|c|c|c|}
\hline \multicolumn{2}{|r|}{ Microorganism } & Sample & Mean \pm SE & $\mathbf{R}$ & $p$-value \\
\hline \multirow{6}{*}{ 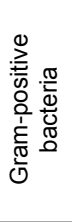 } & \multirow{2}{*}{ Staphylococcus aureus (CECT 240, ATCC 6538P) } & Control & $3.52 \mathrm{E}+05 \pm 2.54 \mathrm{E}+04$ & & \\
\hline & & BB655A0 & $2.17 \mathrm{E}+02 \pm 1.06 \mathrm{E}+02$ & 3.21 & $0.002^{* *}$ \\
\hline & \multirow{2}{*}{ Methicillin-resistant Staphylococcus aureus (CECT 5190, ATCC 43300) } & Control & $2.09 \mathrm{E}+06 \pm 7.68 \mathrm{E}+05$ & & \\
\hline & & BB655A0 & $1.00 \mathrm{E}+01 \pm 0.00 \mathrm{E}+00$ & 5.32 & $4.00 \mathrm{E}-06^{\star *}$ \\
\hline & \multirow{2}{*}{ Vancomycin-resistant Enterococcus faecium (VRE) (CECT 5253) } & Control & $5.07 \mathrm{E}+06 \pm 1.51 \mathrm{E}+06$ & & \\
\hline & & $\mathrm{BB} 655 \mathrm{~A} 0$ & $3.11 \mathrm{E}+04 \pm 1.20 \mathrm{E}+04$ & 2.21 & $0.001^{* *}$ \\
\hline \multirow{8}{*}{ 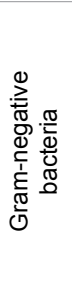 } & \multirow{2}{*}{ Klebsiella pneumoniae (CECT 8453, ATCC 4352) } & Control & $2.17 \mathrm{E}+06 \pm 4.41 \mathrm{E}+05$ & & \\
\hline & & $\mathrm{BB} 655 \mathrm{~A} 0$ & $1.00 \mathrm{E}+01 \pm 0.00 \mathrm{E}+00$ & 5.34 & 4.44E- $07^{* *}$ \\
\hline & \multirow{2}{*}{ Pseudomonas aeruginosa (CECT 110, ATCC 10145) } & Control & $1.88 \mathrm{E}+06 \pm 2.55 \mathrm{E}+05$ & & \\
\hline & & BB655A0 & $3.23 \mathrm{E}+02 \pm 2.60 \mathrm{E}+02$ & 3.77 & $0.002^{\star *}$ \\
\hline & \multirow{2}{*}{ Acinetobacter baumannii (CECT 452, ATCC 15308) } & Control & $1.56 \mathrm{E}+06 \pm 2.92 \mathrm{E}+05$ & & \\
\hline & & $\mathrm{BB} 655 \mathrm{~A} 0$ & $1.00 \mathrm{E}+01 \pm 0.00 \mathrm{E}+00$ & 5.19 & $4.31 \mathrm{E}-07^{\star *}$ \\
\hline & \multirow{2}{*}{ Escherichia coli (CECT 516, ATCC 8739) } & Control & $7.07 \mathrm{E}+06 \pm 1.41 \mathrm{E}+06$ & & \\
\hline & & BB655A0 & $1.00 \mathrm{E}+01 \pm 000 \mathrm{E}+00$ & 5.85 & $5.00 \mathrm{E}-06^{* *}$ \\
\hline
\end{tabular}

Bacterial counts of control and tested samples for each bacterium to determine the bactericide activity of the coating by comparing means ( $p$-value $<0.01$ ). Bold indicates statistically significant results. Control, polyurethane monolayer without silver-based nanoclays. $R, \log$ reduction bacteria. $S E$, standard error. ${ }^{*} p-v a l u e<0.05$. ${ }^{* *} p-v a l u e<0.01$

Table 2: Antibacterial effectiveness of BB655A0 for gram-positive and gram-negative bacteria.

\begin{tabular}{|c|c|c|c|c|c|}
\hline \multicolumn{2}{|r|}{ Microorganism } & Sample & Mean \pm SE & $\mathbf{R}$ & p-value \\
\hline \multirow{6}{*}{ 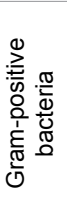 } & \multirow{2}{*}{ Staphylococcus aureus (CECT 240, ATCC 6538P) } & Control & $6.45 \mathrm{E}+05 \pm 1.69 \mathrm{E}+05$ & & \\
\hline & & BB635A1 & $1.00 \mathrm{E}+01 \pm 0.00 \mathrm{E}+00$ & 4.81 & $2.00 \mathrm{E}-06^{\star *}$ \\
\hline & \multirow{2}{*}{ Methicillin-resistant Staphylococcus aureus (CECT 5190, ATCC 43300) } & Control & $9.67 \mathrm{E}+06 \pm 3.03 \mathrm{E}+06$ & & \\
\hline & & BB635A1 & $1.00 \mathrm{E}+01 \pm 0.00 \mathrm{E}+00$ & 5.99 & $4.42 \mathrm{E}-08^{* *}$ \\
\hline & \multirow{2}{*}{ Vancomycin-resistant Enterococcus faecium (VRE) (CECT 5253) } & Control & $1.71 \mathrm{E}+07 \pm 3.53 \mathrm{E}+05$ & & \\
\hline & & BB635A1 & $1.00 \mathrm{E}+01 \pm 0.00 \mathrm{E}+00$ & 5.99 & $1.59 \mathrm{E}-08^{* *}$ \\
\hline \multirow{8}{*}{ 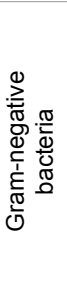 } & \multirow{2}{*}{ Klebsiella pneumoniae (CECT 8453, ATCC 4352) } & Control & $4.53 \mathrm{E}+06 \pm 4.06 \mathrm{E}+05$ & & \\
\hline & & BB635A1 & $1.00 \mathrm{E}+01 \pm 0.00 \mathrm{E}+00$ & 5.66 & $4.69 \mathrm{E}-05^{\star *}$ \\
\hline & \multirow{2}{*}{ Pseudomonas aeruginosa (CECT 110, ATCC 10145) } & Control & $1.19 \mathrm{E}+06 \pm 1.23 \mathrm{E}+05$ & & \\
\hline & & BB635A1 & $1.00 \mathrm{E}+01 \pm 0.00 \mathrm{E}+00$ & 5.08 & 8.29E-08** \\
\hline & \multirow{2}{*}{ Acinetobacter baumannii (CECT 452, ATCC 15308) } & Control & $9.67 \mathrm{E}+06 \pm 1.38 \mathrm{E}+06$ & & \\
\hline & & BB635A1 & $1.00 \mathrm{E}+01 \pm 0.00 \mathrm{E}+00$ & 5.95 & $5.69 \mathrm{E}-08^{* *}$ \\
\hline & \multirow{2}{*}{ Escherichia coli (CECT 516, ATCC 8739) } & Control & $8.93 E+06 \pm 3.17 E+08$ & & \\
\hline & & BB635A1 & $1.00 \mathrm{E}+01 \pm 0.00 \mathrm{E}+00$ & 5.95 & $0.001^{* *}$ \\
\hline
\end{tabular}

Bacterial counts of control and tested samples for each bacterium to determine the bactericide activity of the coating by comparing means ( $p$-value $<0.01$ ). Bold indicates statistically significant results. Control, acrylic coating without antimicrobial agents (silver-based nanoclay and $\mathrm{ZnP}$ ). R, log reduction bacteria. SE, standard error. ${ }^{*} p$-value $<0.05 .{ }^{* *}$-value $<0.01$

Table 3: Antibacterial effectiveness of BB635A1 for gram-positive and gram-negative bacteria.

resistant microorganisms (Table 1). According to the results, $P$. aeruginosa was the less susceptible bacteria to R4.47. P. aeruginosa has been described as a bacteria with an intrinsic resistance mechanism because of pyocyanin synthesis, with reduces silver resulting in an inactive compound $\left(\mathrm{Ag}^{\circ}\right)$ [23]. In addition, it has been reported that $P$. aeruginosa survives to antibiotic and other antimicrobial agents by taking out potent cytotoxins from the cell to the exterior [24,25]. But even in this case BactiBlock ${ }^{\circledR}$-treated coatings decreased the population of this bacterium. Surprisingly, MIC values of the two S. aureus strains are quite different, being higher for MRSA. There is not a priori reason to expect this, but these differences are in accordance with the results shown by Ansari et al., where the MIC values were $12.5 \mu \mathrm{g} / \mathrm{mL}$ and $50 \mu \mathrm{g} / \mathrm{mL}$ for the reference strain of $S$. aureus and MRSA, respectively [26]. However, $\mathrm{R}$ values obtained in the antibacterial coating tests are better for MRSA than for no-resistance S. aureus; although in both cases are higher than the threshold value. Further, the silver-based nanoclay, BactiBlock ${ }^{\otimes} 101$ R4.47, exhibits antimicrobial activity against A. niger at low concentration, confirming the antifungal properties of silver against Candida spp. [27].

On the one hand, silver is taking advantage of quaternary ammonium compounds, the most commonly used disinfectants nowadays because of their high toxicity [28]. On the other hand,

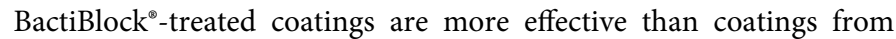
quaternary ammonium salts [29]. These factors would be important to consider when choosing a coating to protect a surface.

Recent market analysis report that the global market for antimicrobial coatings is growing up rapidly [30]. Many different chemical strategies and technologies have been described for antimicrobial coatings. However, silver-based coatings appear to dominate the market [11]. Mainly, the use of silver is promoted because silver has a strong and broad-spectrum antimicrobial activity and mutations to silver resistance are unlikely because of its multitarget mode of action [2]. Besides, it was demonstrated that polymer materials based on silver-based nanoclays exhibit long-term activity because of the controlled silver release and diffusion [17,22]. The controlled release of silver from the coatings can be a clear advantage in antimicrobial surface protection [31]. Although BactiBlock ${ }^{\circ} 635$ A1 Antimicrobial Coating FG antimicrobial activity is higher than BactiBlock 655 A0 Antimicrobial Flooring Protection, this efficacy is hardly better when compared with other similar developed products based on silver nanoparticles [32]. The differences in antibacterial activity between the two coatings should not be result from the differences in the material coating (polyurethane monolayer vs. 


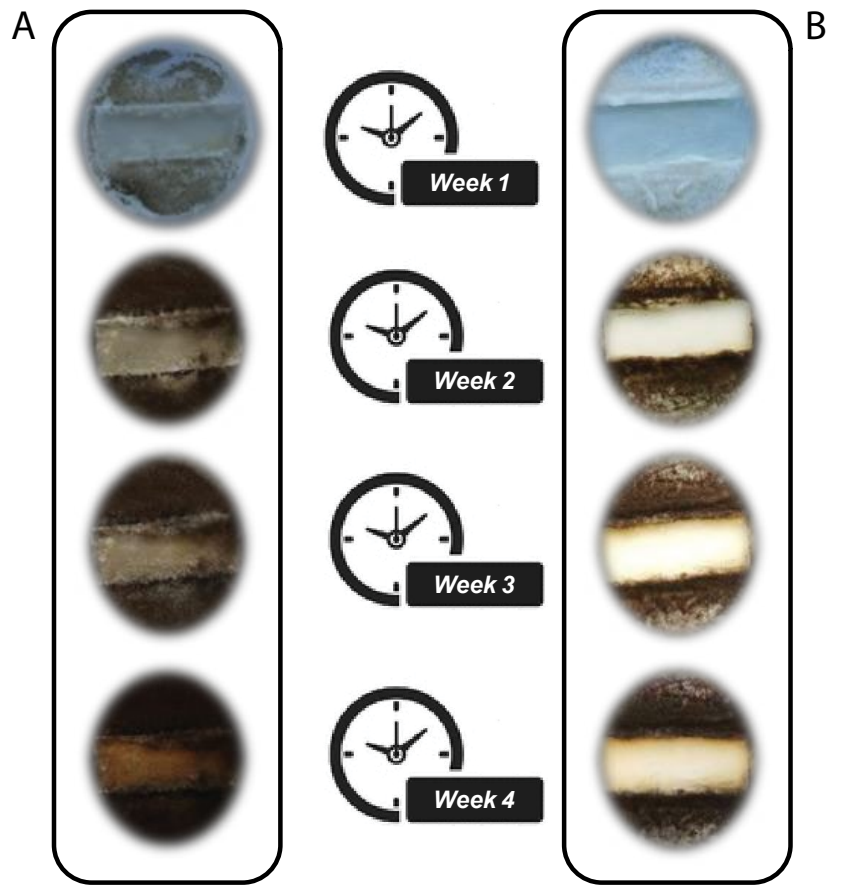

Aspergillus niger was incubated at $25^{\circ} \mathrm{C}$ for 4 weeks on A) untreated samples and B) BB635A1-treated samples

Figure 1: Antifungal effectiveness of BB635A1 according to ISO 846.

acrylic), since both the polyurethane-coating control and the acryliccoating control didn't show bactericidal activity (Table 2 and 3).

The combination of two active agents maximizes the antimicrobial activity of a coating. For this reason, BB635A1, which also contains $2500 \mu \mathrm{g} / \mathrm{mL}$ of $\mathrm{ZnP}$ in its formulation, presents better antibacterial activity than $\mathrm{BB} 655 \mathrm{~A} 0$, since the bacteria reduction values obtained are higher than those of BB655A0 for all the bacteria tested (Table 2 and 3$). \mathrm{ZnP}$ is a compound which boosts the antimicrobial activity of the coating. Tests in vitro showed that polyurethane foam containing $\mathrm{ZnP}$ had antibacterial effect against E.coli, $P$. aeruginosa, Salmonella and $S$. aureus [33]. Besides, it is widely known the antifungal capability of $\mathrm{ZnP}$, which inhibits fungal growth through increased cellular levels of copper, damaging iron-sulphur clusters of proteins essential for fungal metabolism [9]. Although results show that R4.47 has antifungal activity, our experiences let us to combine silver nanoclays and $\mathrm{ZnP}$ to provide a total surface protection against both bacteria and fungi. The combination of two different antimicrobial agents it is not a new idea and has been already introduced in the market [34]. Future actions in antimicrobial coating market should focus on combining the action of two or more antimicrobial agents.

The use of antimicrobial coatings is particularly important in healthcare since it has been proved the role of environmental surfaces in the transmission of hospital-acquired infections (HAIs) [1]. The antimicrobial coatings have the capability of killing pathogens and preventing biofilm formation. Biofilm can persist for many months on inert surfaces facilitating the dissemination of infections after touching [35]. The bacteria selected in this study are the bacteria included in the group of microorganisms named ESKAPE pathogens and Escherichia coli, which is the most frequently isolated microorganism in health- associated infections in Europe [36]. The group of ESKAPE pathogens enclose: E. faecium, S. aureus, K. pneumoniae, A. baumannii, $P$. aeruginosa and $E$. spp. These pathogens are capable of resist to antibiotic and other antimicrobial agents representing new paradigms in pathogenesis, transmission and resistance [37]. The ESKAPE pathogens are also responsible for substantial percentage of healthcare-acquired infections (HAIs) [37,38]. The surface protection against Aspergillus spp. is also essential in healthcare environment since infections due to this fungi cause significant morbidity and mortality [39].

According to our results, BactiBlock ${ }^{\circledR}$-treated coatings could be a potent measure to control harmful microorganisms to which patients and consumers are daily exposed preventing the formation of biofilms on surfaces and, as consequence, the spread of infections in healthcare environment, household and food industry. However, considering that the international standards (JIS Z 2801 and ISO 846) protocols do not reflects real-life application conditions, our future goal is to perform an antimicrobial analysis of coatings in a healthcare scenario. Besides, the durability and the effect of wear on coatings in real-situations need to be assessed, because of it is not possible using these in vitro tests. Hence, further studies in real-life situations should be done to confirm these results.

\section{References}

1. Page K, Wilson M, Parkin IP (2009) Antimicrobial surfaces and their potential in reducing the role of the inanimate environment in the incidence of hospitalacquired infections. Journal of Materials Chemistry 19: 3819-3831.

2. Chopra I (2007) The increasing use of silver-based products as antimicrobial agents: a useful development or a cause for concern? J Antimicrob Chemother 59: 587-590.

3. Russell AD, Hugo WB (1994) Antimicrobial activity and action of silver. Prog Med Chem 31: 351-370.

4. Jung WK, Koo HC, Kim KW, Shin S, Kim SH, et al. (2008) Antibacterial activity and mechanism of action of the silver ion in Staphylococcus aureus and Escherichia coli. Appl Environ Microbiol 74: 2171-2178.

5. Percival SL, Bowler PG, Russell D (2005) Bacterial resistance to silver in wound care. J Hosp Infect 60: 1-7.

6. Pongprayoon T, Nuangchamnong R, Yanumet N (2013) Antimicrobial resistance of clay polymer nanocomposites. Applied Clay Science 86: 179-184.

7. Busolo MA, Lagaron JM (2013) Antimicrobial biocomposites of meltcompounded polylactide films containing silver-based engineered clays Journal of Plastic Film and Sheeting 29: 290-305.

8. Shaw E, Bernstein J, Losee K, Lott WA (1950) Analogs of Aspergillic Acid IV. Substituted 2-Bromopyridine-N-oxides and Their Conversion to Cyclic Thiohydroxamic Acids1. Journal of the American Chemical Society 72: 4362 4364.

9. Reeder NL, Xu J, Youngquist RS, Schwartz JR, Rust RC, et al. (2011) The antifungal mechanism of action of zinc pyrithione. $\mathrm{Br} \mathrm{J}$ Dermatol 165 Suppl 2: 9-12.

10. Faergemann J (2000) Management of seborrheic dermatitis and pityriasis versicolor. Am J Clin Dermatol 1: 75-80

11. Molling JW, Seezink JW, Teunissen BE, Muijrers-Chen I, Borm PJ (2014) Comparative performance of a panel of commercially available antimicrobial nanocoatings in Europe. Nanotechnology, Science and Applications 7: 97-104.

12. Swartjes JJ, Sharma PK, van Kooten TG, van der Mei HC, Mahmoudi M, et al. (2015) Current Developments in Antimicrobial Surface Coatings for Biomedical Applications. Curr Med Chem 22: 2116-2129.

13. Salwiczek M, Qu Y, Gardiner J, Strugnell RA, Lithgow T, et al. (2014) Emerging rules for effective antimicrobial coatings. Trends Biotechnol 32: 82-90.

14. Dancer SJ (2008) Importance of the environment in meticillin-resistant Staphylococcus aureus acquisition: the case for hospital cleaning. Lancet Infect Dis 8: 101-113. 
Citation: Monte-Serrano M, Fernandez-Saiz P, Ortí-Lucas RM, Hernando B (2015) Effective Antimicrobial Coatings Containing Silver-Based Nanoclays and Zinc Pyrithione. J Microb Biochem Technol 7: 398-403. doi:10.4172/1948-5948.1000245

15. Sanborn WR (1963) The relation of surface contamination to the transmission of disease. Am J Public Health Nations Health 53: 1278-1283.

16. Tiller JC, Liao CJ, Lewis K, Klibanov AM (2001) Designing surfaces that kil bacteria on contact. Proc Natl Acad Sci U S A 98: 5981-5985.

17. Busolo MA, Fernandez P, Ocio MJ, Lagaron JM (2010) Novel silver-based nanoclay as an antimicrobial in polylactic acid food packaging coatings. Food Addit Contam Part A Chem Anal Control Expo Risk Assess 27: 1617-1626.

18. ISO $846: 1997$. Plastics - Evaluation of the action of microorganisms

19. Barry AL, Craig WA, Nadler H, Reller LB, Sanders CC, et al. (1999) Methods for determining Bactericidal Activity of Antimicrobial agents; approved guideline M26-A. NCCLS 19

20. Kiehlbauch JA, Hannett GE, Salfinger M, Archinal W, Monserrat C, et al. (2000) Use of the National Committee for Clinical Laboratory Standards Guidelines for Disk Diffusion Susceptibility Testing in New York State Laboratories. Journal of Clinical Microbiology 38: 3341-3348.

21. JIS Z 2801: 2012. Antibacterial products - Test for antibacterial activity and efficacy.

22. Egger S, Lehmann RP, Height MJ, Loessner MJ, Schuppler M (2009) Antimicrobial properties of a novel silver-silica nanocomposite material. Appl Environ Microbiol 75: 2973-2976.

23. Muller M, Merrett ND (2014) Pyocyanin production by Pseudomonas aeruginosa confers resistance to ionic silver. Antimicrob Agents Chemother 58: 5492-5499.

24. Fair RJ, Tor $Y$ (2014) Antibiotics and bacterial resistance in the 21st century. Perspect Medicin Chem 6: 25-64.

25. Li XZ, Nikaido H, Poole K (1995) Role of mexA-mexB-oprM in antibiotic efflux in Pseudomonas aeruginosa. Antimicrob Agents Chemother 39: 1948-1953.

26. Ansari MA, Khan HM, Khan AA, Malik A, Sultan A, et al. (2011) Evaluation of antibacterial activity of silver nanoparticles against MSSA and MRSA on isolates from skin infections. Biology and Medicine 3: 141-146.

27. Kim KJ, Sung WS, Moon SK, Choi JS, Kim JG, et al. (2008) Antifungal effect of silver nanoparticles on dermatophytes. J Microbiol Biotechnol 18: 1482-1484.

28. Melin VE, Potineni H, Hunt P, Griswold J, Siems B, et al. (2014) Exposure to common quaternary ammonium disinfectants decreases fertility in mice. Reproductive Toxicology 50: 163-170.

29. Bakhshi H, Yeganeh $H$, Mehdipour-Ataei S, Shokrgozar MA, Yari A, et al (2013) Synthesis and characterization of antibacterial polyurethane coatings from quaternary ammonium salts functionalized soybean oil based polyols. Materials Science and Engineering 33: 153-164.

30. Antimicrobial Coatings Market- Global Industry Analysis, Size, Analysis Growth and Forecast 2012-2018.

31. Rai M, Yadav A, Gade A (2009) Silver nanoparticles as a new generation of antimicrobials. Biotechnol Adv 27: 76-83.

32. Ciobanu G, llisei S, Luca C (2014) Hydroxyapatite-silver nanoparticles coatings on porous polyurethane scaffold. Mater Sci Eng C Mater Biol Appl 35: 36-42.

33. Dagostin VS, Golçalves DL, Pacheco CB, Almeida WB, Thomé IP, et al. (2010) Bactericidal polyurethane foam mattresses: Microbiological characterization and effectiveness. Materials Science and Engineering 30: 705-708.

34. Ruggiero MA (1991) Paint containing high levels of a pyrithione salt plus a copper salt. U.S. Patent 505715.

35. Bhalla A, Pultz NJ, Gries DM, Ray AJ, Eckstein EC, et al. (2004) Acquisition of nosocomial pathogens on hands after contact with environmental surfaces near hospitalized patients. Infection Control and Hospital Epidemiology 25: 164-167.

36. Zarb P, Coignard B, Griskeviciene J, Muller A, Vankerckhoven V, et al (2012) The European Centre for Disease Prevention and Control (ECDC) pilot point prevalence survey of healthcare-associated infections and antimicrobial use. Euro Surveillance: Bulletin Européen Sur Les Maladies Transmissibles=European Communicable Disease Bulletin.

37. Rice LB (2008) Federal funding for the study of antimicrobial resistance in nosocomial pathogens: no ESKAPE. J Infect Dis 197: 1079-1081.

38. Pendleton JN, Gorman SP, Gilmore BF (2013) Clinical relevance of the ESKAPE pathogens. Expert Rev Anti Infect Ther 11: 297-308.

39. Person AK, Chudgar SM, Norton BL, Tong BC, Stout JE (2010) Aspergillus niger: an unusual cause of invasive pulmonary aspergillosis. J Med Microbiol 59: 834-838. 